GLA activity intracellularly in IS than peripheral blood, $\mathrm{p}=0.001$ (see Abstract P179 Figure 1), and extracellularly in IS supernatant versus plasma in males alone $(p<0.05)$.

Conclusions Sputum GLA activity is lower in male AFD patients than controls. However AFD subjects had significantly higher GLA activity in lung than blood. Measured airway obstruction in AFD was mild, though common. We speculate that the higher levels of lung enzyme found in AFD patients, on or off enzyme replacement, may contribute to the relative preservation of pulmonary function compared to other organ systems.

\section{P180 SPUTUM EOSINOPHIL POSITIVITY TO TAILOR STEROID MANAGEMENT OF SEVERE ASTHMATICS}

doi:10.1136/thx.2010.151043.31

G Tavernier, C Pris-Picard, R Gore, R Niven. University of Manchester, Wythenshawe Hospital, Manchester, UK

The use of sputum eosinophil count in asthma clinics is rapidly expanding as it has been reported as being a useful indicator of the worsening of asthma symptoms and that its normalisation reduces asthma exacerbations and admissions. Without additional steroids, levels of sputum eosinophils have been shown to be highly variable in severe asthmatic patients. Furthermore, precise patient phenotyping is increasingly becoming important as our understanding of the physiopathology of severe asthma widens. We introduced sputum differential cell counting in our severe asthma clinic, with a view to first reducing sputum eosinophils below 3\% by augmenting anti-inflammatory therapy, and attempting steroid withdrawal once patients became sputum eosinophil negative (E-). To date, 264 patients have been investigated for sputum eosinophils, using induction with nebulised sodium chloride if necessary and suitable. This paper presents our yearly update of the anti-inflammatory (steroid) therapy of the first successive patients with at least two successful sputum counts (current $n=71$ ), specifically investigating patients' management in the light of their positive sputum eosinophil levels at baseline assessment. Twenty patients were sputum eosinophil positive $(E+)$ on their initial visit and 25 had reduced eosinophil levels $(p=0.001)$ on a subsequent visit, including 14 becoming $\mathrm{E}-$. Nineteen were offered a trial of steroid augmentation: 11 patients with a trial of IM triamcinolone (all patients had subsequent reduced eosinophils levels, 9 becoming $\mathrm{E}-$, $\mathrm{p}=0.003)$;

5 patients with increased oral prednisolone treatment (four patients with reduced eosinophils levels, one becoming E-);

3 with increased inhaled steroid therapy (all with reduced eosinophil levels, 1 becoming $\mathrm{E}-$ ).

$66 \%$ of patients with uncontrolled sputum eosinophilia were treated with an increase in anti-inflammatory maintenance therapy. Sputum eosinophil levels decreased for $95 \%$ of these as already reported, but only 11/19 achieved full control of sputum eosinophilia with $2 / 11$ failing to normalise eosinophils despite IM triamcinolone (representing a population of confirmed steroid resistance. Sputum eosinophil negativity used as a surrogate marker for asthma control has been shown to be an essential tool in identification and management of patients with asthma at risk of deterioration and admission

\section{P181 BETTER ASTHMA CONTROL WITH MONTELUKAST THAN SALMETEROL IN ARG-16 HOMOZYGOUS CHILDREN WITH ASTHMA}

doi:10.1136/thx.2010.151043.32

${ }^{1} \mathrm{~K}$ Basu, ${ }^{2} \mathrm{H}$ P Donald, ${ }^{3} \mathrm{~B} J$ Lipworth, ${ }^{4} \mathrm{R}$ Tavendale, ${ }^{2} \mathrm{D}$ F Macgregor, ${ }^{5} \mathrm{~S}$ A Ogston, ${ }^{4} \mathrm{C}$ N A Palmer, 'S Mukhopadhyay. ${ }^{1}$ Royal Alexandra Children's Hospital, Brighton and
Sussex Medical School, Brighton, UK; ${ }^{2}$ Paediatric Asthma and Allergy Research Group, NHS Tayside, Perth, UK; ${ }^{3}$ Asthma and Allergy Research Group, Division of Medicine and Therapeutics, Ninewells Hospital, Dundee, UK; ${ }^{4}$ Population Pharmacogenetics Group, Biomedical Research Institute, University of Dundee, Dundee, UK; ${ }^{5}$ Division of Clinical and Population Sciences and Education, University of Dundee, Dundee, UK

Introduction and Objectives Diminished efficacy of salmeterol for improving asthma control is increased in children with asthma homozygous for arginine-16 (Arg16) allele of the ADRB2. Concerns have been raised regarding the efficacy and safety of long-term salmeterol use in patients with asthma. We investigated whether there is a genotype-specific difference in long-term asthma control with montelukast compared to salmeterol in individuals homozygous for $\operatorname{Arg} 16$ of $A D R B 2$

Methods In this pragmatic randomised controlled trial, 62 children (5-18 years) with asthma, carrying Arg/Arg16 genotype and exacerbation of asthma at least once within the previous year, were randomly assigned to receive Flixotide ${ }^{\circledR}$ (fluticasone propionate) via accuhaler (Diskus) dry powder inhaler device plus oral montelukast (Group I); or Seretide ${ }^{\circledR}$ (salmeterol plus equivalent dose of fluticasone) via accuhaler dry powder inhaler device plus placebo for montelukast (Group II). No effort was made to blind the prescribed inhaler. The primary end point was school absence, prospectively measured as individual events over the period of 1 year.

Results No significant difference was observed in school absences $(p=0.097)$ between the treatment groups. The use of reliever medication was significantly decreased in Group I compared to Group II $(p=0.004)$. Total exacerbations were reduced in Group 1 compared to Group $2(p=0.049)$. Self-reported symptoms were significantly improved in Group I compared to Group II (morning cough $\mathrm{p}=0.018$; morning wheeze $\mathrm{p}=0.001$; morning dyspnoea $p=0.008$; night wheeze: $p=0.004$; night dyspnoea: $p=0.001)$. A significant improvement in quality of life as per the Juniper paediatric asthma quality of life questionnaire was observed in Group I compared to Group II (activity limitation score $(\mathrm{p}=0.004)$, symptom score $(p=0.009)$, emotional function score $(p=0.002))$.

Conclusion In individuals homozygous for Arg16 of the ADRB2 locus, montelukast is an effective step up medication compared with salmeterol. Montelukast, as an asthma controller added on to inhaled steroid, improved asthma symptoms and quality of life, while reducing the use of reliever medication, in comparison to salmeterol. A larger randomised controlled trial is required, comparing asthma control with salmeterol versus montelukast in the genotypic subgroups in $A D R B 2$, and to explore the cost-effectiveness of genotypespecific controller therapies in children with asthma.

\section{P182 ADENOSINE POTENTIATES HUMAN MAST CELL FIBRINOLYTIC ACTIVITY}

doi:10.1136/thx.2010.151043.33

${ }^{1} \mathrm{M}$ J Sereda, ${ }^{2} \mathrm{P}$ Bradding, ${ }^{1} \mathrm{C}$ Vial. ${ }^{1}$ Department of Cell Physiology and Pharmacology, University of Leicester, ${ }^{2}$ Department of Infection, Immunity and Inflammation, University of Leicester

We investigated whether adenosine, a potent contributor to the regulation of pulmonary function, can modulate human lung mast cell (HLMC) fibrinolytic activity. Tissue plasminogen activator (tPA) activity and tPA transcript expression levels from a human mast cell line (HMC-1) and HLMC were monitored following adenosine application. Adenosine potentiated mast cell tPA activity and tPA gene expression in a dose-dependent manner. Adenosine effects were abolished in the presence of adenosine deaminase. HMC-1 cells predominantly expressed adenosine $A_{2 A}$ and $A_{2 B}$ receptor transcripts $\left(A_{2 A}>>A_{2 B}>A_{3}>>A_{1}\right)$. In addition to $A_{2 A}$ and $A_{2 B}, A_{3}$ receptor transcripts were also abundantly found in HLMC $\left(A_{2 A}>>A_{2 B}>>A_{3}>>A_{1}\right)$. Pharmacological and signalling studies 
suggest that the $A_{2 A}$ receptor is the major subtype accounting for adenosine-induced mast cell tPA activity. Finally, the supernatant from HMC-1 cells treated with adenosine (24h) significantly increased fibrin clot lysis, while ZM241385, an $\mathrm{A}_{2 \mathrm{~A}}$ receptor antagonist, abolished this effect. This study provides the first data to demonstrate the potentiating effect of adenosine on mast cell tPA activity and fibrin clot lysis.

\section{P183 GLOBAL BURDEN OF ALLERGIC BRONCHOPULMONARY ASPERGILLOSIS (ABPA) COMPLICATING ASTHMA}

doi:10.1136/thx.2010.151043.34

${ }^{1} \mathrm{D}$ W Denning, ${ }^{2} \mathrm{~A}$ Pleuvry, ${ }^{3} \mathrm{D} \mathrm{C}$ Cole. ${ }^{1}$ The University of Manchester, Manchester, UK; ${ }^{2}$ Oncalex, High Peak, Derbyshire, UK; ${ }^{3}$ Dalla Lana School of Public Health, University of Toronto, Toronto, Canada

Background ABPA may complicate asthma in some patients. The potential global ABPA burden remains unknown, limiting its prioritisation for both population and clinical responses.

Methods We estimated the number of adults with asthma, using the GINA statistics as the baseline dataset and this derived equation: Adult Prevalence $(\mathrm{AP})=$ total prevalence $\times$ adult population $/(0.88$ paediatric population + adult population). This method provided results which were compatible with more direct sources on Scotland (Ananadan, 2010), North Africa (Nafti, 2009) and the USA (CDC stats, 2008). Two period prevalence rates available on ABPA in asthmatic patients are $0.72 \%$ (Ireland; Donnelly, 1991) and 3.5\% (New Zealand; Eaton, 2000) (eliminating the non-classical cases from both papers) so we used a mean of $2.1 \%$ (range $0.72-3.5 \%$ ). We estimated case burdens by WHO region and for the UK and USA.

Results By WHO region, the ABPA burden estimates are: Europe, 466891 (range 160 077-778 152); Americas, 704926 (range 2416891174877); Eastern Mediterranean, 187963 (range 64 444-313272); Africa, 294058 (range 100820-490 097); Western Pacific, 881860 (range 302 352-1469 766); South East Asia, 614353 (range $210635-$ 1023 922); and global, 3150052 (range $1080018-5250086$ ) cases. The UK adult asthma and ABPA burdens are estimated to be $7.1 \mathrm{M}$ and 149901 (range 51395-249835) cases, respectively, with those for the US being 24.5M and 515787 (range 176841-859645) cases.

Conclusions ABPA is probably more common globally than has been appreciated. A lack of sufficient population research using current fungal diagnostic approaches and clinical research on antifungal therapy effects on the course of ABPA among different populations, limits our estimates' utility.

\section{P184 CAN WE PREDICT ASTHMA EXACERBATIONS IN WORKING- AGE ADULTS?}

doi:10.1136/thx.2010.151043.35

${ }^{1} \mathrm{~S} J$ MacNeill, ${ }^{1} \mathrm{~A}$ B Jones, ${ }^{2} \mathrm{C}$ J P Smith, ${ }^{2} \mathrm{R}$ Hubbard, ${ }^{1} \mathrm{P}$ Cullinan. ${ }^{1}$ National Heart and Lung Institute (Imperial College), London, UK; ${ }^{2}$ Division of Epidemiology and Public Health (University of Nottingham), Nottingham, UK

Introduction Little information exists on the prevalence and risk factors of asthma exacerbations in the general population. We used GP records to determine whether we can predict exacerbations in adults from their medical history.

Methods Using the Health Improvement Network database, weidentified all patients aged $16-40$ years with "current asthma" ( $\geq 1$ asthma prescription between $01 / 07 / 98$ and $01 / 07 / 00$ ). Three types of asthma exacerbations were studied: "hospital" defined as events resulting in attendance at A\&E or admission; "GP" defined as events occurring during out-of-hours consultations; and "prednisolone" defined as non-repeat prescriptions of oral prednisolone for asthma.
Results 73462 patients were identified. They were on average 28 years old and $56 \%$ were female. $36,762(50 \%)$ were registered for at least 5 years pre-qualification and 1 year post. Of these, $0.3 \%$ had at least one hospital exacerbation in the first year post, $2.4 \%$ had at least one GP exacerbation and $8.3 \%$ had at least one prednisolone exacerbation. Women and those prescribed a reliever and preventor at qualification were more likely to have exacerbations (see Abstract P184 Table 1). The prevalence of exacerbations was associated with an increasing number and increasingly recent history of exacerbations pre-qualification.

Abstract P184 Table 1 Prevalences of at least one exacerbation in the first year post-qualification

\begin{tabular}{|c|c|c|c|}
\hline & Hospital & GP & Prednisolone \\
\hline \multicolumn{4}{|l|}{ Sex } \\
\hline Male & $0.2 \%$ & $2.1 \%$ & $7.1 \%$ \\
\hline \multirow[t]{2}{*}{ Female } & $0.4 \%$ & $2.6 \%$ & $9.2 \%$ \\
\hline & $p=0.001$ & $p=0.001$ & $\mathrm{p}<0.001$ \\
\hline \multicolumn{4}{|l|}{ Prescriptions at qualification } \\
\hline Reliever and preventor & $0.5 \%$ & $3.9 \%$ & $14.3 \%$ \\
\hline \multirow[t]{2}{*}{ Other } & $0.3 \%$ & $1.7 \%$ & $5.8 \%$ \\
\hline & $\mathrm{p}=0.001$ & $\mathrm{p}<0.001$ & $\mathrm{p}<0.001$ \\
\hline \multicolumn{4}{|c|}{ Number of exacerbations* in the 5 years pre-qualification } \\
\hline \multicolumn{4}{|c|}{0} \\
\hline 1 & $0.3 \%$ & $1.7 \%$ & $5.9 \%$ \\
\hline 2 & $3.3 \%$ & $9.0 \%$ & $14.9 \%$ \\
\hline \multirow[t]{3}{*}{$3+$} & $17.5 \%$ & $12.5 \%$ & $25.0 \%$ \\
\hline & $18.8 \%$ & $30.8 \%$ & $47.8 \%$ \\
\hline & $\mathrm{p}<0.001$ (trend) & $\mathrm{p}<0.001$ (trend) & $\mathrm{p}<0.001$ (trend) \\
\hline \multicolumn{4}{|c|}{ Time since the last pre-qualificaiton exacerbation* } \\
\hline$<1$ year & $11.8 \%$ & $20.5 \%$ & $39.5 \%$ \\
\hline $1-2$ years & $8.8 \%$ & $11.0 \%$ & $22.3 \%$ \\
\hline $2-3$ years & $6.5 \%$ & $9.2 \%$ & $16.2 \%$ \\
\hline \multirow[t]{2}{*}{$3+$ years } & $1.9 \%$ & $5.8 \%$ & $13.6 \%$ \\
\hline & $\mathrm{p}<0.001$ (trend) & $\mathrm{p}<0.001$ (trend) & $\mathrm{p}<0.001$ (trend) \\
\hline
\end{tabular}

*Of the same type.

Discussion These results show that while few have hospital exacerbations, GP and prednisolone exacerbations are comparatively common. For all types, a previous and recent history of exacerbations increases the risk of future exacerbations.

\section{Challenges in smoking cessation P185 PUBLIC ATTITUDES TO SMOKING IN CARS}

doi:10.1136/thx.2010.151043.36

${ }^{1} \mathrm{E}$ De Lacy, ${ }^{1} \mathrm{R}$ Morrison, ${ }^{1} \mathrm{M}$ Dockrell, ${ }^{1} \mathrm{~T}$ Buchanan, ${ }^{2} \mathrm{~K}$ E Lewis. ${ }^{1}$ Action on Smoking and Health, England; ${ }^{2}$ Swansea University, Wales

Background Passive smoking is increasingly associated with adverse health effects. The new UK Government is considering its tobacco control policy.

Aim To record public attitudes on potential legislation regarding smoking in cars

Methods We commissioned a survey of the YouGov ${ }^{\circledR}$ Plc British panel of $185000+$ people (aged 18+). An email was sent to panellists, selected at random using a sophisticated sampling matrix, to be representative of each country. Three surveys were conducted between 25 and 30 March 2009. We obtained answers from $\mathrm{n}=10895$ adults in England, $\mathrm{n}=1023$ adults in Wales, and $\mathrm{n}=1157$ adults in Scotland. The results for all three countries were merged at analysis stage and re-weighted to be representative of the overall GB population. We had data from 13075 adults, 52\% female, mean age 